Revista Brasileira de Agricultura Irrigada v.8, no. 5, p.403 - 410, 2014

ISSN 1982-7679 (On-line)

Fortaleza, CE, INOVAGRI - http://www.inovagri.org.br

DOI: $10.7127 /$ rbai.v8n500257

Protocolo 257.14 - 23/06/2014 Aprovado em 19/08/2014

\title{
DISTRIBUIÇÃO DE POTÁSSIO APLICADO VIA VINHAÇA EM LATOSSOLO VERMELHO AMARELO E NITOSSOLO VERMELHO
}

\author{
Pedro Henrique Pinto Ribeiro ${ }^{1}$, João Alberto Lelis $\mathrm{Neto}^{2}$, Marconi Batista Teixeira ${ }^{3}$, Hugo \\ Orlando Carvallo Guerra ${ }^{4}$, Nelmício Furtado da Silva ${ }^{5}$; Fernando Nobre Cunha ${ }^{6}$
}

\section{RESUMO}

No solo, o potássio é móvel e, portanto, sujeito a perdas por lixiviação. Rica em potássio, a vinhaça é geralmente usada como fertilizante, especialmente nos canaviais. Mas o uso excessivo desta substância pode contaminar rios e lençóis freáticos pelo excesso de potássio, se a aplicação não for manejada adequadamente. Portanto, objetivou-se, com o presente trabalho, avaliar o deslocamento do potássio em colunas segmentadas com dois tipos de solo não saturado sob aplicação da vinhaça. Foram confeccionadas colunas de acrílico com dimensões de $75 \mathrm{~cm}$ de altura por $5 \mathrm{~cm}$ de diâmetro, preenchidas com dois tipos de solo, arenoso (Latossolo Vermelho) e argiloso (Nitossolo). Os resultados mostraram que a percolação do $\mathrm{K}^{+}$está diretamente relacionada com o tipo de solo, interagindo-se mais com a fração sólida do solo argiloso quando comparado com o solo arenoso. No solo argiloso houve maior concentração de potássio nas primeiras camadas de solo, ao contrário do solo arenoso onde a distribuição foi mais homogênea entre as camadas.

Palavras-chave: lixiviação, movimento de soluto, cana-de-açúcar, contaminação.

\section{POTASSIUM DISTRIBUTION APPLIED THROUGH VINASSE IN OXISOL AND RED NITOSOL}

\footnotetext{
ABSTRACT

In soil potassium is mobile and therefore subject to leaching losses. Rich in potassium, the waste water (vinasse) from sugar and ethanol industry is generally used as a fertilizer, especially in the sugar cane fields. But the substance can contaminate rivers and groundwater

1 Mestre em Irrigação, Universidade Federal de Campina Grande - Campina Grande - PB, e-mail: pedroirri@gmail.com

2 Departamento de Engenharia de Biossistemas, Escola Superior de Agricultura "Luiz de Queiroz" ESALQ/USP, Piracicaba, SP.

${ }^{3}$ Eng. Agrônomo, Prof. Dr. em Agronomia, IFGoiano - Câmpus Rio Verde, e-mail: marconibt@ gmail.com

${ }^{4}$ Prof. Titular, UFCG, Departamento de Engenharia Agrícola, CEP 58109-970, Campina Grande, PB, e-mail: hugo_carvallo@hotmail.com

5 Mestrando em Ciências Agrárias - Agronomia, IFGoiano - Câmpus Rio Verde, e-mail: nelmiciofurtado@gmail.com

Mestrando em Ciências Agrárias - Agronomia, IFGoiano - Câmpus Rio Verde, e-mail: fernandonobrecunha@hotmail.com
} 
by excess potassium, if not used adequately. Therefore, this study aimed to evaluate the displacement of potassium in segmented column of different unsaturated soil under application of vinasse. Acrylic columns of dimensions of $75 \mathrm{~cm}$ (height) x $5 \mathrm{~cm}$ (diameter) were filled with 2 different soils coarse-textured Oxisol (sandy) and fine-textured Oxisol (loam). The results showed that the percolation of the $\mathrm{K}^{+}$is directly related to soil type, with loam soil interacting more with the solid fraction as compared to sandy soil. Loam soil showed higher concentration of potassium in the first layers of soil, unlike the sandy soil which showed homogeneous distribution in soil layers.

Keywords: leaching, solute movement, sugarcane, contamination.

\section{INTRODUÇÃO}

Impulsionado pela crescente demanda interna por etanol, e dependendo do sucesso de sua exportação, estima-se que em menos de 10 anos o Brasil terá que dobrar a quantidade de cana-de-açúcar colhida para atender o mercado. Assim, aumentando-se a quantidade de vinhaça produzida. O constituinte principal da vinhaça é a matéria orgânica, basicamente sob a forma de ácidos orgânicos e, em menor quantidade, por cátions como o $\mathrm{K}, \mathrm{Ca}$ e $\mathrm{Mg}$.

Segundo Anselmi (2008), a vinhaça melhora o condicionamento da subsuperfície do solo e proporcionam ganhos ao menos de cinco toneladas de cana por hectare em relação ao potássio proveniente de adubo químico na cana-de-açúcar.

Quando depositada no solo, a vinhaça pode promover melhoria na fertilidade; todavia, quando usada para este fim, as quantidades não devem ultrapassar sua capacidade de retenção de íons, isto é, as dosagens devem ser mensuradas de acordo com as características de cada solo, uma vez que este possui quantidades desbalanceadas de elementos minerais e orgânicos, podendo ocorrer à lixiviação de vários desses íons, sobretudo do nitrato e do potássio (SILVA et al., 2007; LELIS NETO, 2008).

Estudos realizados verificaram que doses crescentes de vinhaça aumentam a concentração de $\mathrm{K}$ trocável, principalmente nas camadas mais superficiais do argissolo estudado (BRITO et al., 2005). A habilidade do solo em reter o potássio aplicado é muito dependente da capacidade de troca de cátions do solo, assim, as quantidades de argila e matéria orgânica no solo, influenciam, fortemente, no grau de lixiviação. Os solos com alta capacidade de troca têm grande habilidade em reter o potássio aplicado; entretanto, a lavagem deste elemento é frequentemente um problema em solos arenosos (LIBARDI, 2005).

O uso de modelos numéricos para simular o fluxo de água em solo não saturado tem sido progressivamente difundido; são exemplos os métodos das diferenças finitas e os elementos finito, citados por Klute (1986). Para Silva et al. (2012) modelos de simulação podem proporcionar um entendimento melhor dos processos que ocorrem no solo, relativos ao deslocamento de solutos, constituindo ferramentas aplicáveis a estudos de minimização de impactos ao meio ambiente. O sucesso da simulação e resolução das equações que predizem o deslocamento de solutos no solo é necessário à determinação dos parâmetros de transporte que influenciam na relação solosoluto.

Assim, objetivou-se com o presente estudo avaliar o deslocamento do íon potássio $\left(\mathrm{K}^{+}\right)$aplicado em dois tipos distintos de solo (arenoso e argiloso) acondicionados em colunas segmentadas, buscando compreender o deslo- 
camento deste íon em diferentes solos sob aplicação de vinhaça.

\section{MATERIAL E MÉTODOS}

O experimento foi conduzido no Laboratório de Física do Solo do Departamento de Engenharia de Biossistemas da Escola Superior de Agricultura "Luiz de Queiroz" ESALQ/USP. Foram utilizados dois tipos de solo coletados no município de Piracicaba-SP. As coletas foram realizadas em perfis característicos para cada tipo de solo na camada de 0 a $0,20 \mathrm{~m}$. Os materiais de solo foram secados e peneirados em uma malha de $2 \mathrm{~mm}$. Os solos utilizados foram classificados como Latossolo Vermelho Amarelo de textura arenosa e Nitossolo Vermelho Eutrófico de textura argilosa (EMBRAPA, 1999).

Os solos foram submetidos à análise granulométrica utilizando o método de Bouyoucos (Tabela 1). Por meio da granulometria pode-se inferir a movimentação e adsorção dos nutrientes ao longo do tempo, pois na textura argilosa ao possuir um maior teor de argila e silte, espera-se que a movimentação dos nutrientes, com carga positiva, na solução desse solo seja menor que em relação ao solo arenoso.

Tabela 1. Granulometria dos solos utilizados no experimento.

\begin{tabular}{cccc}
\hline Solo & $\begin{array}{c}\mathrm{g} \mathrm{Kg}^{-1} \\
\text { Argila }\end{array}$ & $\begin{array}{c}\mathrm{g} \mathrm{Kg}^{-1} \\
\text { Silte }\end{array}$ & $\begin{array}{c}\mathrm{g} \mathrm{Kg}^{-1} \\
\text { Areia }\end{array}$ \\
\hline $\begin{array}{c}\text { Latossolo Vermelho } \\
\text { Amarelo }\end{array}$ & 22,98 & 7,28 & 69,74 \\
$\begin{array}{c}\text { Nitossolo Vermelho } \\
\text { Eutrófico }\end{array}$ & 49,80 & 11,18 & 39,01 \\
\hline
\end{tabular}

O delineamento experimental foi em parcelas subdivididas com 2 tratamentos (2 diferentes solos), 10 profundidades $(0,0-0,07$; $0,07-0,14 ; \quad 0,14-0,21 ; \quad 0,28-0,35 ; \quad 0,35-0,42$; $0,42-0,49 ; 0,49-0,56 ; 0,56-0,63$ e 0,63-0,70 cm) e 3 repetições. Para realização do experimento utilizou-se colunas de acrílico para uma melhor visualização da frente de molhamento com as dimensões de $0,70 \mathrm{~m}$ de altura e $0,05 \mathrm{~m}$ de diâmetro. A coluna era segmentada em 10 anéis de $0,07 \mathrm{~m}$ de altura e foram montadas 3 colunas para cada solo conforme mostra a Figura 1. Em seguida, preencheu-se as colunas com solo, mantendo a densidade do solo entorno de 1,29 a $1,30 \mathrm{~g} \mathrm{~cm}^{-3}$, o mais próximo possível do encontrado a campo.

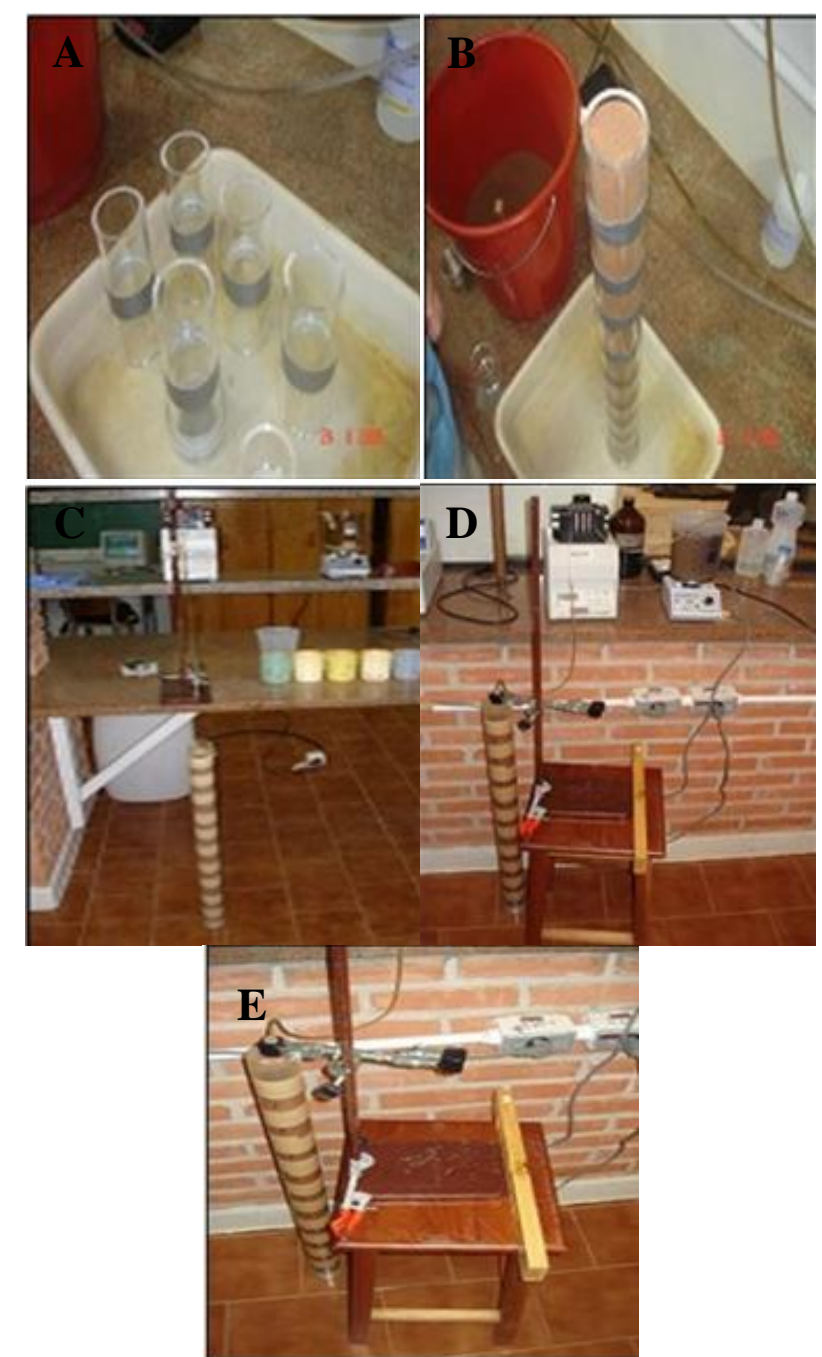

Figura 1. (A) Preparação dos anéis; (B) Montagem da coluna segmentada; (C) Preparação para ajuste de Vazão e VIB da coluna; (D) Funcionamento do sistema com a coluna e (E) Percolação da Vinhaça. 
Foi utilizado um anel superior de menor tamanho (0,05 $\mathrm{m}$ de altura) com a função de proteger as camadas de solo inferiores no momento da aplicação da vinhaça. A vazão de vinhaça aplicada foi de $39 \mathrm{ml} \mathrm{h}^{-1}$, onde a mesma se equivale à velocidade de infiltração básica. A aplicação de vinhaça foi realizada utilizando-se uma bomba peristáltica, de forma a manter a vazão constante e um agitador magnético para que a matéria orgânica da vinhaça não decantasse. Tomou-se como padrão não deixar que a frente de molhamento atingisse o final da coluna. $\mathrm{O}$ fornecimento de vinhaça foi interrompido quando atingiu a metade do oitavo anel $(0,53 \mathrm{~m})$, iniciando-se à desmontagem da coluna e as determinações dos valores de umidade do solo e concentração do potássio, referente a cada anel.

Após o término da coluna, preparou-se uma pasta homogênea de cada segmento da coluna, onde foram retiradas duas amostras. A primeira foi levada à estufa a $110{ }^{\circ} \mathrm{C}$ por um período de 24 horas para determinação posteriormente do conteúdo de água (umidade) em cada segmento. A segunda amostra foi seca a temperatura ambiente para determinação da concentração de potássio em cada anel, utilizando o fotômetro de chama, seguindo método da Embrapa (1999). De posse dos valores experimentais da umidade volumétrica referente a cada anel e da concentração do potássio, procedeu-se a verificação do perfil de umidade e da concentração de potássio para cada tipo de solo.

A vinhaça utilizada no experimento foi adquirida de uma usina de álcool no município de Piracicaba, sendo coletada próxima a bica de descarga antes de ser destinada aos canais de transporte no campo para evitar uma contaminação ou adição de partículas de solo, sendo que todos os cuidados foram tomados para que a amostra obtida fosse representativa. A vinhaça foi analisada no laboratório para determinação de sua composição, tendo suas características físico-químicas expressas na Tabela 2.

Tabela 2. Caracterização físico-química da vinhaça utilizada na coluna de solo.

\begin{tabular}{ccc}
\hline Descrição & Unidade & Valores \\
\hline $\mathrm{DBO}^{1}$ & $\mathrm{mg} \mathrm{l}^{-1}$ & $10.974,5$ \\
$\mathrm{DQO}^{2}$ & $\mathrm{mg} \mathrm{l}^{-1}$ & $62.085,5$ \\
$\mathrm{SDT}^{3}$ & $\mathrm{mg} \mathrm{l}^{-1}$ & 14.886 \\
$\mathrm{CE}^{4}$ & $\mathrm{dS} \mathrm{m}^{-1}$ & 11,5 \\
$\mathrm{pH}$ & - & 4,5 \\
$\mathrm{~K}$ & $\mathrm{mg} \mathrm{l}^{-1}$ & 2.934 \\
$\mathrm{Na}$ & $\mathrm{mg} \mathrm{l}^{-1}$ & 51 \\
\hline
\end{tabular}

${ }^{1} \mathrm{DBO}$ - demanda bioquímica de oxigênio; ${ }^{2} \mathrm{DQO}-$ demanda química de oxigênio; ${ }^{3} \mathrm{SDT}$ - sólidos dissolvidos totais; ${ }^{4} \mathrm{CE}$ - condutividade elétrica.

Os resultados das variáveis de resposta foram analisados utilizando-se o teste $\mathrm{F}$ para análise de variância, segundo o delineamento em blocos casualizados, e, em função da significância, serão ajustadas equações de regressão dos atributos avaliados e para as diferentes reposição hídrica será realizado o teste de Tukey.

\section{RESULTADOS E DISCUSSÃO}

De acordo com os dados observa-se que não houve diferença estatística significativa na concentração de potássio entre os solos analisados Tabela 3. Entretanto, houve diferença estatística ao nível de $1 \%$ de probabilidade de erro, da concentração de potássio, em profundidade dentro da coluna de solo. Assim como, houve diferença significativa $(\mathrm{p}<0,01)$ entre a interação tipo de solo e profundidade (Tabela 4). 
Tabela 3. Resultado da análise de variância (ANOVA) para concentração de potássio nos dois solos avaliados e em profundidade nas colunas de acrílico.

\begin{tabular}{ccccc}
\hline $\begin{array}{c}\text { Fontes de } \\
\text { Variação }\end{array}$ & G.L & S.Q & Q & MF \\
\hline Trat. (Solo) - a & 1 & 229,54613 & 229,54613 & $0,8476^{\mathrm{ns}}$ \\
Resíduo a & 4 & 1083,27897 & 270,81974 & \\
\hline $\begin{array}{c}\text { Trat. } \\
\text { (Profundidade) b }\end{array}$ & 9 & 195672,1162 & 21741,34625 & $502,2856^{* *}$ \\
$\begin{array}{c}\text { Int. Ta x Tb } \\
\text { Resíduo b }\end{array}$ & 9 & 17258,91521 & 1917,65725 & $44,3032^{* *}$ \\
\hline & 6 & 1558,25391 & 43,28483 & \\
\hline Total & 59 & 215802,1104 & &
\end{tabular}

\footnotetext{
**ignificativo ao nível de $1 \%$ de probabilidade $(\mathrm{p}<$ $0,01)$.
}

Tabela 4. Variação média da concentração de potássio $\left(\mathrm{K}^{+}\right)$em profundidade na coluna de acrílico nos solos estudados, Latossolo Vermelho Amarelo (arenoso) e Nitossolo Vermelho Eutrófico (argiloso).

$\begin{array}{ccc}\begin{array}{c}\text { Profundidade } \\ (\mathrm{m})\end{array} & \text { Nitossolo Vermelho } & \text { Latossolo Vermelho } \\ & \text { Eutrófico (Argiloso) } & \text { Amarelo (Arenoso) }\end{array}$

\begin{tabular}{ccc}
\hline $0,0-0,07$ & $199,57 \mathrm{ppm} \mathrm{aA}^{\mathrm{s}}$ & $120,10 \mathrm{ppm} \mathrm{bA}^{\mathrm{ns}}$ \\
$0,07-0,14$ & $156,28 \mathrm{ppm} \mathrm{aB}^{\mathrm{s}}$ & $110,22 \mathrm{ppm} \mathrm{bA}^{\mathrm{s}}$ \\
$0,14-0,21$ & $86,83 \mathrm{ppm} \mathrm{aC}^{\mathrm{s}}$ & $87,08 \mathrm{ppm} \mathrm{aB}^{\mathrm{s}}$ \\
$0,21-0,28$ & $15,71 \mathrm{ppm} \mathrm{bD}^{\mathrm{ns}}$ & $61,96 \mathrm{ppm} \mathrm{aC}$ \\
$0,28-0,35$ & $3,03 \mathrm{ppm} \mathrm{bD} \mathrm{Cs}^{\mathrm{ns}}$ & $34,36 \mathrm{ppm} \mathrm{aD}^{\mathrm{s}}$ \\
$0,35-0,42$ & $2,57 \mathrm{ppm} \mathrm{aD}^{\mathrm{ns}}$ & $12,45 \mathrm{ppm} \mathrm{aE}^{\mathrm{ns}}$ \\
$0,42-0,49$ & $2,23 \mathrm{ppm} \mathrm{aD}$ & $2,69 \mathrm{ppm} \mathrm{aE}^{\mathrm{ns}}$ \\
$0,49-0,56$ & $0,63 \mathrm{ppm} \mathrm{aD}^{\mathrm{ns}}$ & $0,72 \mathrm{ppm} \mathrm{aE}^{\mathrm{ns}}$ \\
$0,56-0,63$ & $1,84 \mathrm{ppm} \mathrm{aD}^{\mathrm{ns}}$ & $0,00 \mathrm{ppm} \mathrm{aE}^{\mathrm{ns}}$ \\
$0,63-0,70$ & $0,00 \mathrm{ppm} \mathrm{aD}^{\mathrm{ns}}$ & $0,00 \mathrm{ppm} \mathrm{aE}^{\mathrm{ns}}$ \\
\hline
\end{tabular}

*As médias seguidas pela mesma letra, maiúscula na coluna e minúscula na linha, não diferem estatisticamente entre si, pelo Teste de Tukey ao nível de $5 \%$ de probabilidade, $\left(^{s}=\right.$ significativo; ${ }^{\text {ns }}=$ não significativo).
Os resultados mostram que até a profundidade de $14 \mathrm{~cm}$ houve maior concentração de $\mathrm{K}^{+}$no solo argiloso quando comparado com o solo arenoso (Tabela 4). De 14 a $21 \mathrm{~cm}$ não houve diferença estatística da concentração de $\mathrm{K}^{+}$entre os solos. De 21 a $35 \mathrm{~cm}$ a concentração de $\mathrm{K}^{+}$se inverteu, foi maior no solo arenoso. De 35 a $70 \mathrm{~cm}$ não foi observado diferença estatística em concentração de $\mathrm{K}^{+}$nos diferentes solos avaliados. Resultados estes de acordo com os encontrados por (BRITO, 2005; BEBÉ, 2009; PAULINO et al., 2011), em estudo sobre avaliação de solos em diferentes períodos de aplicação com vinhaça, onde afirma que as maiores reações da vinhaça com o solo foram na camada de 0-0,2 m. No entanto, Paula et al. (1999) observaram em estudo com solos de baixo potencial produtivo, aumento do $\mathrm{K}$ nas camadas de $0-20 \mathrm{~cm}$ e de 20 $40 \mathrm{~cm}$.

Observa-se na Figura 2 a variação da concentração de potássio $\left(\mathrm{K}^{+}\right)$para as diferentes profundidades ao longo da coluna de acrílico para os solos avaliados. As concentrações do íon potássio apresentaram variações no solo, encontrando-se valores entre 216 a 5 ppm ou mg L ${ }^{-1}$, para o solo argiloso (Figura 2A) e entre 128 a 1,3 ppm ou $\mathrm{mg} \mathrm{L}^{-1}$ para o solo arenoso (Figura 2B). As concentrações de potássio encontradas para o solo argiloso apresentaram maior concentração na camada superficial da coluna segmentada em comparação ao solo arenoso que apresentou melhor distribuição do potássio nas diferentes profundidades estudadas. Para Silva et al. (2012) as perdas de nutrientes causadas pelo fenômeno da lixiviação são importantes pelo fato de significar baixas eficiências de utilização de nutrientes pelas culturas e, por consequência, menores rendimentos. 
Ribeiro et al.

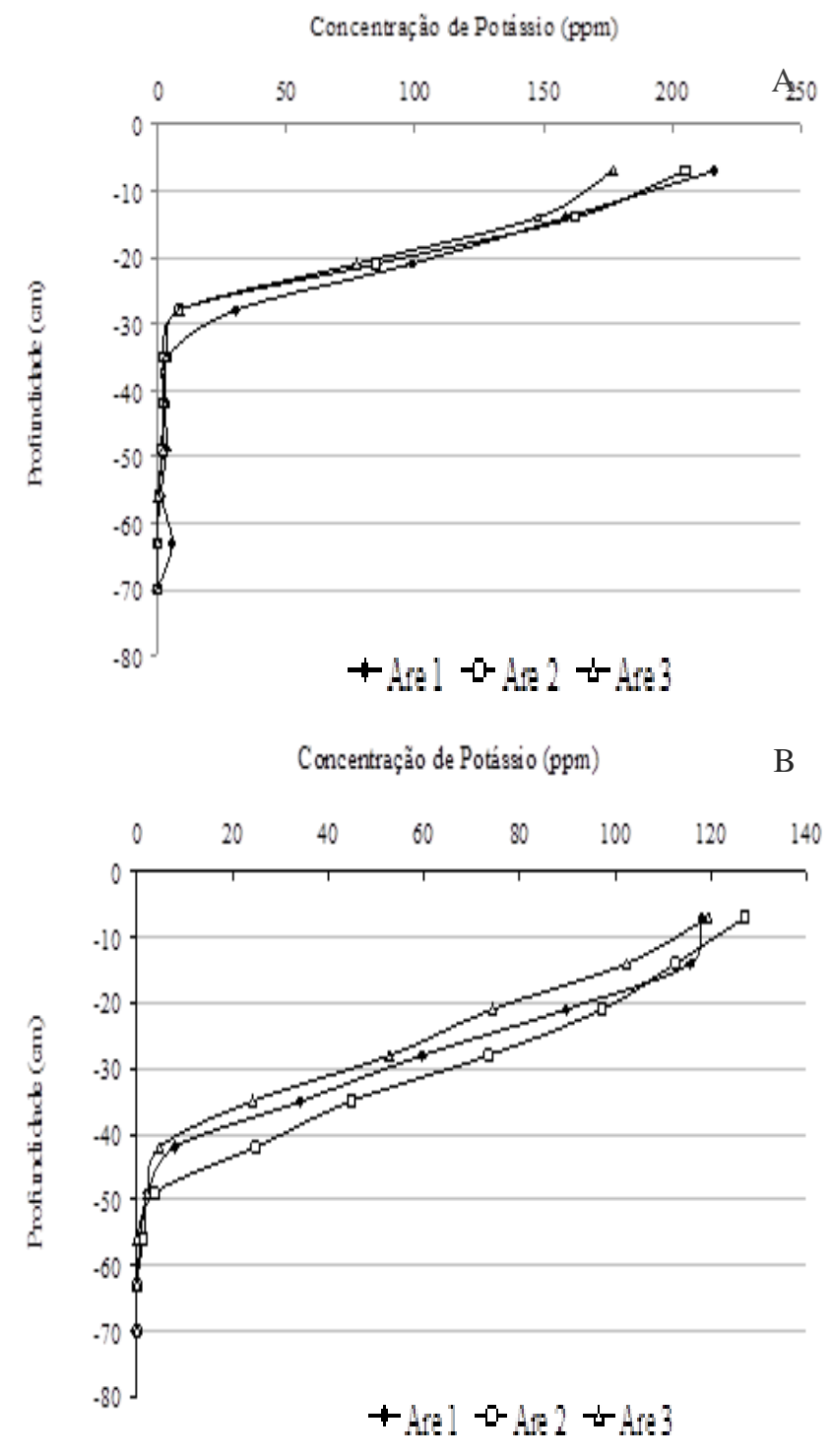

Figura 2. Variação da concentração de potássio $\left(\mathrm{K}^{+}\right)$nas 3 colunas de cada solo estudado, (A): Nitossolo Vermelho Eutrófico (argiloso) e (B): Latossolo Vermelho Amarelo (arenoso).

Estas diferenças foram provavelmente devido às características físicas dos dois solos. De acordo com o relatado por Sengik et al. (1988) estas alterações podem existir dependendo do tipo e da característica física do solo. Para Miranda et al. (2005) o transporte de potássio no solo está relacionado com o tamanho dos agregados, sendo mais fácil o transporte daqueles de menor tamanho, com o tempo de difusão, a geometria do meio poroso (inter e intra-agregados), a textura do solo e o tipo de mineral de argila.
Segundo Brito et al. (2007) em estudo sobre concentração de cátions tratados com vinhaça, verificaram as concentrações de $\mathrm{K}$ de 9,21 e 16 para a menor dose, e de 10,15 e 21,54 $\mathrm{mg} \mathrm{L}^{-1}$ para a maior dose no Argissolo e Espodossolo, respectivamente, aos 30 dias, sendo estas concentrações consideradas baixas.

Observou-se que no solo arenoso houve um carreamento do potássio até a profundidade de $0,70 \mathrm{~m}$, comprovando a hipótese, que os solos arenosos possuem baixa adsorção e capacidade de troca catiônica (Figura 3A). Tal situação pode ser explicada pelo fato do potássio, se tratar de um cátion, que fica adsorvido em solos com alta capacidade de troca catiônica, diferentemente dos resultados encontrados por Brito et al. (2005) que encontraram acréscimo de potássio em profundidade, assim como menor mobilidade de K em solos arenosos. Canellas et al. (2003) trabalhando em Cambissolo, não verificou aumento de potássio em profundidade, em concordância com os resultados encontrados neste estudo para Latossolo Vermelho Amarelo (arenoso) e Nitossolo Vermelho Eutrófico (argiloso); sugerindo que a distribuição de vinhaça não foi uniforme, concordando com Corá et al. (2004).

Umidade Volum étrica $\left(\mathrm{cm}^{2} / \mathrm{cm}^{2}\right)$

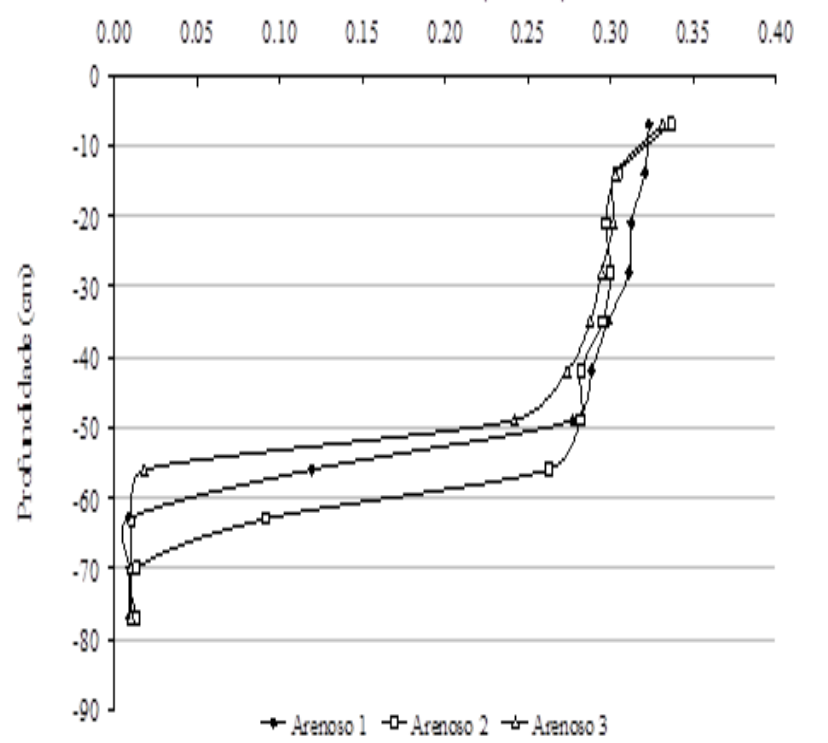




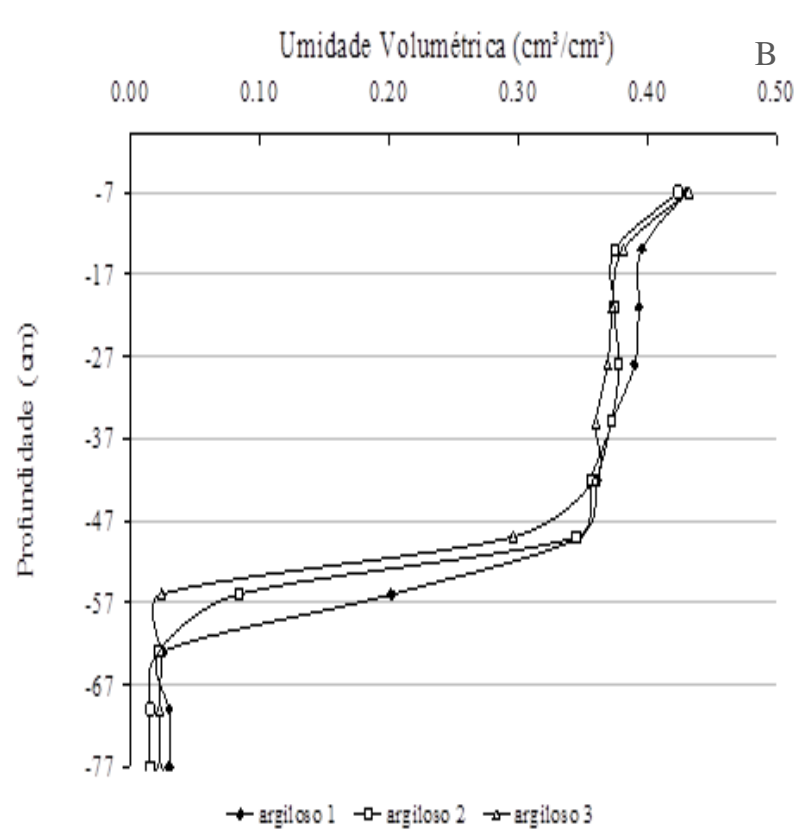

Figura 3. Variação do conteúdo de água nas 3 colunas de cada solo estudados, (A). Latossolo Vermelho Amarelo (arenoso) e (B). Nitossolo Vermelho Eutrófico (argiloso).

Costa et al. (2000) avaliaram a extração de potássio por três tipos de cápsulas porosas e constataram que a concentração de $K$ na solução extraída foi menor do que a concentração na solução aplicada.

$\mathrm{Na}$ avaliação do conteúdo da vinhaça aplicada nos diferentes solos estudados, é possível verificar maior retenção de água na superfície do solo argiloso em relação ao solo arenoso (Figura 3B). Isso explica uma maior concentração de $\mathrm{K}$ na camada superficial do solo argiloso em comparação ao solo arenoso. Barber (1962) afirma que a partir do momento em que houver saturação das cargas elétricas, o excedente permanece na solução do solo e, caso isso ocorra, o atributo com maior influência na mobilidade passa a ser o conteúdo de água volumétrica no solo.

\section{CONCLUSÕES}

O solo argiloso apresentou maior interação com o íon potássio $\left(\mathrm{K}^{+}\right)$em relação ao solo arenoso;

As concentrações de potássio foram decrescentes ao longo da coluna de acrílico em ambos os solos estudados, sendo este efeito mais acentuado no solo argiloso.

O solo arenoso apresentou distribuição mais homogênea entre as camadas avaliadas que o solo argiloso.

\section{REFERÊNCIAS BIBLIOGRÁFICAS}

ANSELMI, R. Alta de fertilizantes abre canal à vinhaça. Jornalcana - TECNOLOGIA AGRÍCOLA. Ed.4. Campinas, 2008. 30 p.

BABER, S. A. A diffusion and mass-flow concept of soil nutrient availability. Soil Science, v. 93, n.2, p. 39-49, 1962.

BEBÉ, F. V.; ROLIM, M. M.; PEDROSA, E. M. R.; SILVA, G. B.; OLIVEIRA, V. S. Avaliação de solos sob diferentes períodos de aplicação de vinhaça. Revista Brasileira de Engenharia Agrícola e Ambiental, v.13, p.781-787, 2009.

BRITO, F. L.; ROLIM, M. M.; PEDROSA, E. M. R. Concentração de cátions presentes no lixiviado de solos tratados com vinhaça. Revista de Engenharia Agrícola. Jaboticabal, v.27, n.3, p.773-781. 2007.

BRITO, F. L.; ROLIM, M. M.; PEDROSA, E. M. R. Teores de potássio e sódio no lixiviado e em solos após a aplicação de vinhaça. Revista Brasileira de Engenharia Agrícola e Ambiental, Campina Grande, v.13, n.9, Suplemento, p. 52-56, 2005.

CANELlaS, L. P.; VELlOSO, A. C. X.; MARCIANO, C. R.; RAMALHO, J. F. G. P.; RUMJANEK,V. M.; REZENDE， C. E.; SANTOS, G. A. Propriedades químicas de um Cambissolo cultivado com cana-de-açúcar, com 
preservação de palhiço e adição de vinhaça por longo tempo. Revista Brasileira de Ciência do Solo, Viçosa, v. 27, n.5, p. 935-944. 2003.

COSTA, A.C.S.; SUZUKI, A.A.; LIBERDI, P.L.; PINTRO, J.C.; TORMENA, C.A.; SOUZA JUNIOR, I.G.; SENGIK, E. Extração de $\mathrm{K}^{+}$e $\mathrm{Na}^{+}$por cápsulas de cerâmica porosa. Acta Scientiarum, Maringá, v.22, n.4, p.1.0231.029, 2000.

CORÁ, J. E.; ARAÚJO, A. V.; PEREIRA, G. T.; BERALDO, J. M. G. Variabilidade espacial de atributos do solo para adoção do sistema de agricultura de precisão na cultura de canadeaçúcar. Revista Brasileira de Ciência do Solo, v.28, p.1013-1021,2004.

Empresa Brasileira de Pesquisa Agropecuária EMBRAPA. Sistema Brasileiro de Classificação de Solos - Brasília: EMBRAPA Produção de informação; Rio de Janeiro: EMBRAPA Solos, 1999, xxvi, 412 p.

KLUTE, A. Water retention: Laboratiry methods. In: KLUTE, A. ed. Methods of soil análisis. 2.ed. Madison, Americam Society of Agronomy, p.635-660, 1986.

LELIS NETO, J. A. Monitoramento de componentes químicos da vinhaça aplicados em diferentes tipos de solo. 89p. 2008. Dissertação (Mestrado) - Escola Superior de Agricultura Luiz de Queiroz, 2008.

LIBARDI, P. L. Dinâmica da água no solo. São Paulo: Edusp, 2005. 335 p.
MIRANDA, J. H.; DUARTE, S. N.; LIBARDI, P. L.; FOLEGATTI, M. V. Simulação do deslocamento de potássio em colunas verticais de solo não-saturado. Engenharia. Agrícola, Jaboticabal, v.25, n.3, p.677-685, 2005.

PAULA, M. B.; et al. Uso da vinhaça no abacaxizeiro em solo de baixo potencial de produção. Pesquisa Agropecuária Brasileira, v.7, p.1217-1222, 1999.

PAULINO, J.; et al. Estudo exploratório do uso da vinhaça ao longo do tempo. II. Características da cana-de-açúcar. Revista Brasileira de Engenharia Agrícola Ambiental, Campina Grande, v.15, n.3, p.244249, 2011.

SENGIK, E.; RIBEIRO, A. C.; CONDE, A. R. Efeito da vinhaça em algumas propriedades de amostras de dois solos de Viçosa (MG). Revista Brasileira de Ciência do Solo, Viçosa, v.12, n.5, p. 11-15, 1998.

SILVA, M. A. S.; GRIEBELER, N. P.; BORGES, L. C. Uso de vinhaça e impactos nas propriedades do solo e lençol freático. Revista Brasileira de Engenharia Agrícola e Ambiental, Campina Grande, v.11, n.1, p. 108114, 2007.

SILVA, N. F.; LELIS NETO, J. A.; TEIXEIRA, M. B.; CUNHA, F. N.; MIRANDA, J. H.; COELHO, R. D. Distribuição de solutos em colunas de solo com vinhaça. Irriga, Edição especial, p.340-350, 2012. 